\title{
Spatio-Temporal Variations of Precipitation Extremes in the Yangtze River Basin (1960-2002), China
}

\author{
Qiang Zhang ${ }^{1,2}$, Xiaohong Chen ${ }^{1,2}$, Becker Stefan ${ }^{3}$ \\ ${ }^{1}$ Department of Water Resources and Environment, Sun Yat-sen University, Guangzhou, China \\ ${ }^{2}$ Key Laboratory of Water Cycle and Water Security in Southern China of Guangdong \\ High Education Institute, Sun Yat-sen University, Guangzhou, China \\ ${ }^{3}$ Department of Environmental, Geographic, and Geological Sciences (EGGS), Lehman College, \\ The City University of New York, 315 Gillet Hall, 250 Bedford Park Blvd. West, Bronx, NY, USA \\ E-mail:ylian@illinois.edu \\ Received December 10, 2010; revised January 11, 2010; accepted January 21, 2010.
}

\begin{abstract}
Daily precipitation data during 1960-2002 from 150 stations in the Yangtze River basin were analyzed with the help of linear trend analysis. Highest 5-day and 10-day precipitation amount (R5D and R10D) and percentile daily precipitation maxima (prec $95 p$ for $95^{\text {th }}$ percentile and prec $99 p$ for $99^{\text {th }}$ percentile) were accepted as the precipitation extreme index. The frequency of the R5D and R10D was in downward trend, this phenomenon is more obvious in the middle Yangtze River basin; The stations with total precipitation of R5D and R10D are in significant upward trend ( $>95 \%$ confidence level) are mostly located in the lower Yangtze River basin and the south-western part of the Yangtze River basin; 2) the spatial distribution of the frequency of total precipitation of the percentile daily precipitation maxima is similar to that of R5D and R10D. However the frequency of prec95p and prec99p is in significant upward trend. The upward trend of total precipitation changes of prec95p and prec99p is more obvious than that of frequency of prec95p and prec99p. The regions dominated by upward trend of frequency/total precipitation of prec $95 \mathrm{p}$ and prec $99 \mathrm{p}$ are also the lower Yangtze River basin and south-western part of the Yangtze River basin. Therefore the occurrence probability of the flash floods in the lower Yangtze River basin and south-western part of the Yangtze River basin will be greater.
\end{abstract}

Keywords: Extreme Precipitation, Linear Trend, Spatial Distribution Pattern, Yangtze River Basin

\section{Introduction}

In recent years, the greenhouse effect has become the focus of large-scale investigations. Tremendous impacts of the observed global warming on the global hydrological cycle at various spatial and temporal scales are likely to be more sensitive $[1,2]$. Some physical and empirical research results, together with General Circulation Model (GCM) experiments suggested that global warming may lead to a more intense hydrological cycle and with an associated increase in the frequency and/or magnitude of heavy precipitation [3]. Effects of precipitation changes on hydrological process rely on the type of changes in number of rainy days and/or daily precipitation amount. Increase in daily precipitation amount will be favorable for increase of watershed runoff and river discharge [4].

The global warming may lead to the increasing inten- sity and magnitude of extreme climatic events. Extreme climatic changes may exert more serious negative impacts on human society. Increases of extreme climatic events are drawing increasing concerns from meteorologists and hydrologists of the world [5-7]. Some studies indicate that over the last half century weather patterns have become more variable, with more frequent and more intense rainfall events $[8,9]$, changes in the timing and location of precipitation [5]. The Yangtze River (Changjiang) (Figure 1), being the longest river in China and the third longest river in the world, plays a vital role in the economic development of China. The river originates in the Qinghai-Tibet Plateau and flows about 6300 $\mathrm{km}$ eastwards to the East China Sea. The Yangtze floods occurred annually, being the most serious natural disasters with tremendous anti-disaster expenditures, being known as serious trouble of China [10]. Historical records 


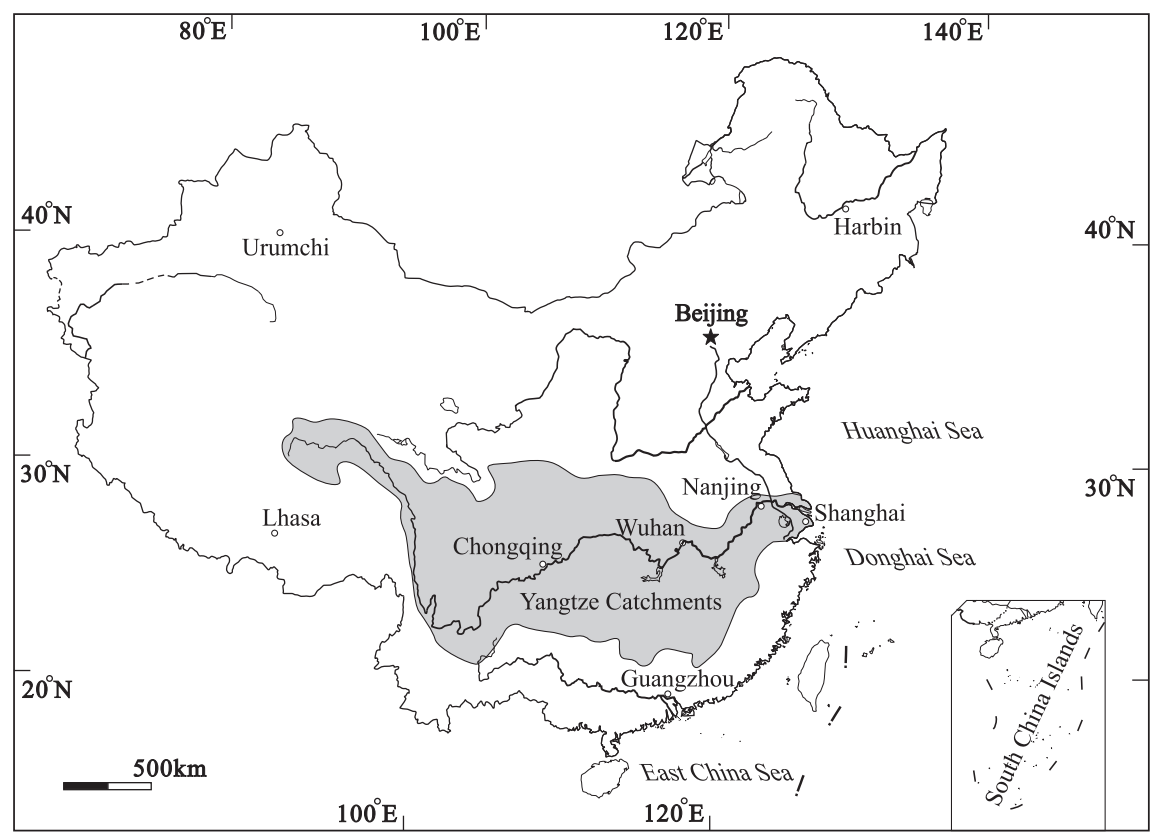

Figure 1. Location of the Yangtze River basin.

of the Yangtze floods during recent 200 years are complete. $19^{\text {th }}$ century is the third cold period of the global little ice age, there are 8 floods occurred to the Yangtze River basins. $20^{\text {th }}$ century is characterized by global warming, about 19 floods occurred to the Yangtze River. The frequency is clearly higher than that of $19^{\text {th }}$ century. The close connections between the warmest years and high frequency of floods are worthy of attention. Connections between temperature, precipitation and discharge of the Yangtze River basin indicate that discharge changes are in fine agreement with precipitation. If seen from annual changes, good agreement also happened to temperature, precipitation and discharge [11]. Severe precipitation events are among the most devastating weather phenomena since they are frequently followed by flash floods and other sever weather conditions such as hail [12]. It is widely accepted that variability of frequency and intensity of extreme climatic events are likely to exert much more impact on nature and human society than that from the mean climatic value [13]. Changes of extreme climatic events and their possible influences on human society are receiving increasing concerns from hydrologists and meteorologists of the world [14-16]. As for the extreme precipitation changes in the Yangtze River basin, Zhang et al., [11] analyzed the spatial distribution and trends in the frequency of precipitation extremes during 1960-2003 using daily precipitation data from 147 stations in the Yangtze River basin with the help of Mann-Kendall trend analysis and IDW (Inverse Distance Weighted) interpolation technology with Arcview package. The definition of the ex- treme precipitation is that the daily precipitation exceeding the $95^{\text {th }}$ percentile in a data set is defined as extreme precipitation for each station. In the present paper, daily precipitation exceeding the $95^{\text {th }}$ percentile and $99^{\text {th }}$ percentile was defined as extreme precipitation of two magnitudes. At the same time, 5-day extreme daily precipitation and 10-day extreme daily precipitation were also analyzed for further research.

The main objective of this paper is to demonstrate the changes of the extreme precipitation in different parts of the Yangtze River basin, showing the possible regional responses to global climatic changes.

\section{Data and Methods}

Considering the influences of topography on climatic changes, in this paper, the whole Yangtze River basin was divided into three parts [11] based on longitude (Table 1). Daily precipitation data of 150 stations in the Yangtze River basin were from China Meteorological Administration (CMA). There are 35 stations located in the upper Yangtze River basin, 73 stations located in the middle Yangtze River basin and 42 stations located in

Table 1. Three regions of the Yangtze River basin analyzed in the paper.

\begin{tabular}{lccc}
\hline & Upper & Middle & Lower \\
\hline Longitude & $\sim 104^{\circ} \mathrm{E}$ & $104-113^{\circ} \mathrm{E}$ & $113^{\circ} \mathrm{E} \sim$ \\
Mean altitude (m. a.s.1) & 2551 & 627 & 113 \\
Number of stations & 10 & 27 & 14 \\
\hline
\end{tabular}


the lower Yangtze River basin. The time interval is from January, 1960 to December, 2002. The homogeneity of the precipitation data was detected by calculating the von Neumann ratio $\left(\mathrm{Q} / \mathrm{n}^{-0.5}\right.$ and $\left.\mathrm{R} / \mathrm{n}^{-0.5}\right)$ with the help of Bayesian procedures [17]. The precipitation data sets of all stations are significantly homogeneous. Highest 1 day, 5 day and 10 day precipitation amount (R1D, R5D and R10D) are accepted as index for extreme precipitation (www.ncdc.noaa.gov/oa/wmo/ccl) for annual extreme precipitation. Percentile daily precipitation/temperature maxima (prec $95 p$ for $95^{\text {th }}$ percentile and prec $99 p$ for $99^{\text {th }}$ percentile) was widely accepted as a standard to define daily extreme precipitation/tempera- ture $[12,18,19]$.

Simple linear regression will be used in this paper for trend test. The simple linear regression method is a parametric T-test method, which consists of two steps, fitting a linear simple regression equation with the time $t$ as independent variable and the precipitation variable, $\mathrm{Y}$ as dependent variable, and testing the statistical significance of the slope of the regression equation. The parametric T-test requires the data to be tested is normally distributed. The normality of the data series is first tested in the study by applying the Kolmogorov-Smirnov test. The method first compares the specified theoretical cumulative distribution function (in our case normal distribution) with the sample cumulative density function based on observations, then calculates the maximum deviation, $\mathrm{D}$, of the two. If, for the chosen significance level, the observed value of $\mathrm{D}$ is greater than or equal to the critical tabulated value of the Kolmogorov-Smirnov statistic, the hypothesis of normal distribution is rejected.

\section{Results}

\subsection{Annual Extreme Precipitation Changes}

Figure 2 shows the linear trends of the highest 5-day precipitation amount, Figure 2A and Figure 2B show the trends of frequency and total precipitation amount of highest 5 day precipitation amount respectively. Figure 2A indicates that frequency of R5D of $69 \%$ stations of the Yangtze River basin is in downward trend, (without considering whether the trend is significant or not). The stations with frequency of R5D in upward trend are mostly located in the south-western part and south-eastern part of the Yangtze River basin. The Middle Yangtze River basin is dominated by stations with frequency of R5D in downward trend. In the Yangtze Delta region, the downward trend of the frequency of R5D are significant at $>95 \%$ confidence level. In the middle Yangtze River basin, frequency of R5D of $81 \%$ stations is in downward trend (Figure 3).

Figure 2B and Figure 3 demonstrate that total precipitation of R5D of the Yangtze River basin is mostly in upward trend, the stations with total precipitation of R5D in upward trend account for about $63 \%$ of the total stations. Total precipitation of R5D of 27 stations is in significant trend, wherein, stations with total precipitation of R5D in significant upward trend account for $67 \%$ of the total stations with total precipitation of R5D in significant trend. Figure 2B also indicates that stations with total precipitation of R5D in significant trend are mostly located in lower Yangtze River basin, and those in significant downward trends are mostly located in the middle Yangtze River basin.

Changes of frequency/total precipitation of R10D show the similar patterns. Stations with frequency of R10D in downward trend account for about $53 \%$ of the total stations, wherein, 25 stations are in significant trend. There are 15 stations with frequency of R10D in signifycant upward trend and 12 stations with frequency of R10D in significant downward trend. It seems that frequency of R10D of stations in significant upward-trend is mostly located in upper Yangtze River basin (Figure. 4A, Figure 3). As for the total precipitation of R10D (TR10D), altogether 96 stations have TR10D in upward

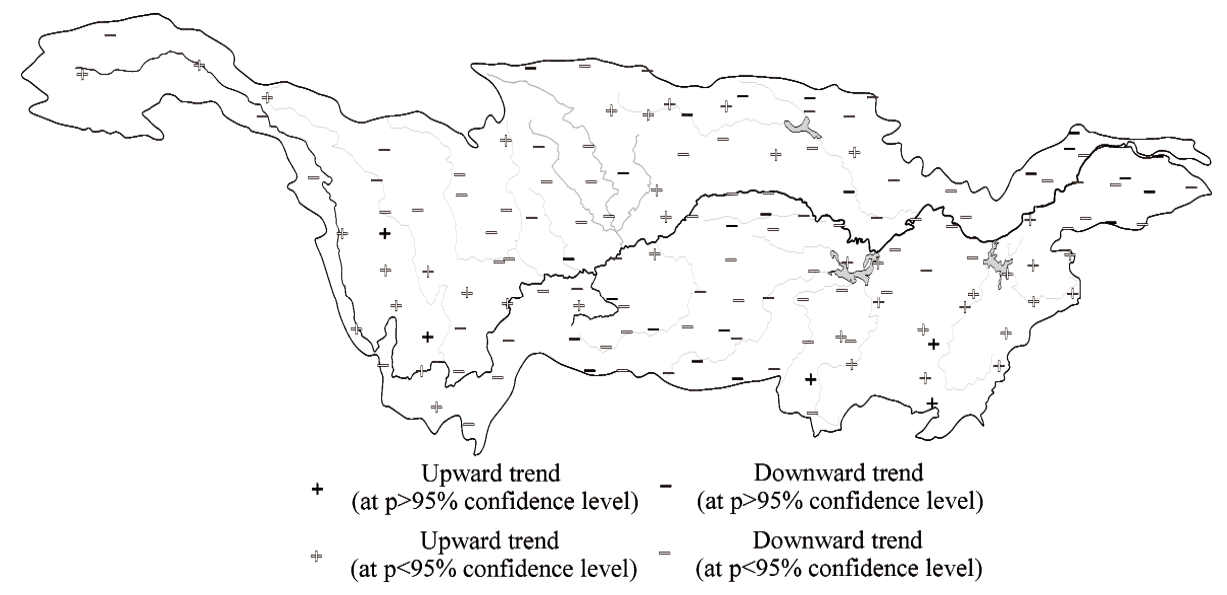

(A) 


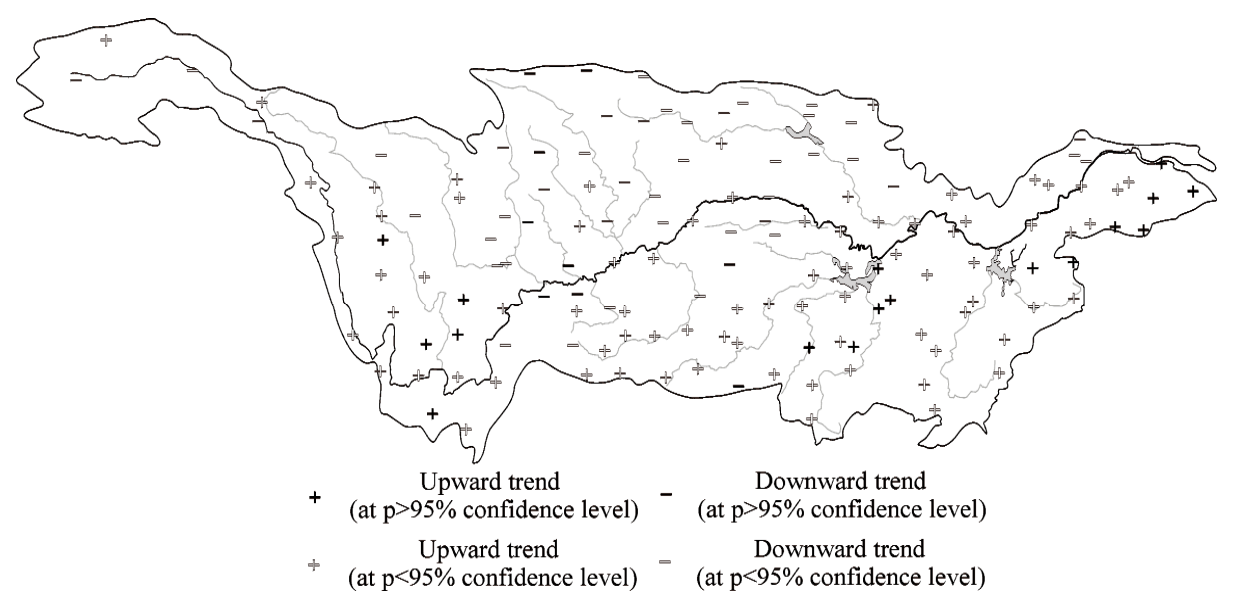

(B)

Figure 2. Spatial distribution of trends of highest 5-day precipitation amount. A: Frequency of highest 5 day precipitation amount; B: Total of highest 5-day precipitation amount.

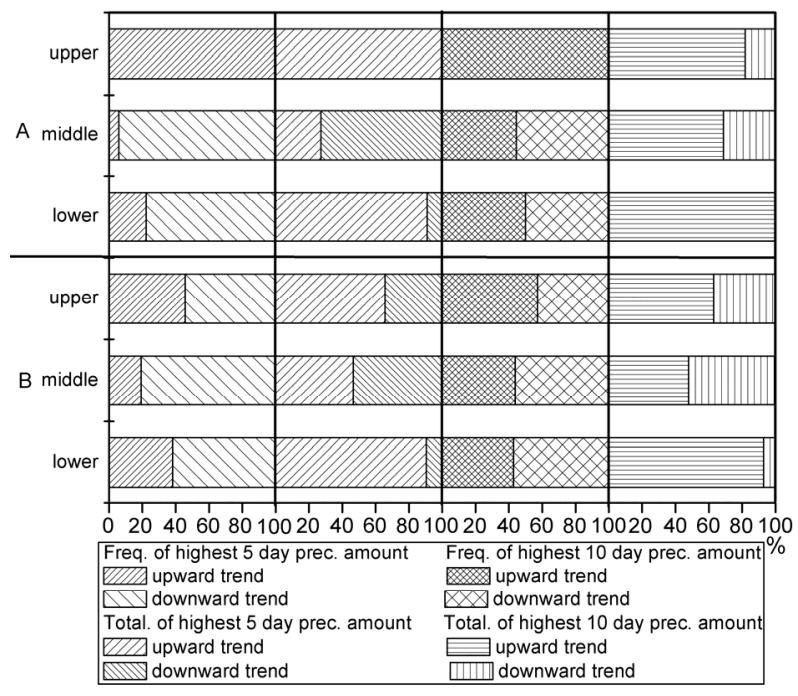

Figure 3. Ratio of stations with total precipitation in upward/downward trend to the total stations $(B)$ and ratio of stations with frequency of extreme precipitation in significant upward/downward trend ( $>95 \%$ confidence level) to the total stations with frequency of extreme precipitations in significant upward/downward trend $(>95 \%$ confidence level) (A) in upper, middle and lower reaches of the Yangtze River basin respectively

trend (whether this trend is significant or not) in the Yangtze River basin. Most stations with TR10D in upward trend are mostly located in the lower Yangtze River basin (Figure 4B, Figure 3). The middle Yangtze River basin is dominated by the stations with TR10D in downward trend.

When it comes to the stations with TR10D in significant trend, altogether 37 stations have TR10D in significant trends, wherein 20 stations have TR10D in signifi- cant upward trend ( $>95 \%$ confidence level), accounting for $74 \%$ of the total stations with TR10D in significant trends (Figure 3). 11 stations with TR10D in significant upward trend are located in the middle Yangtze River basin and 9 stations located in the upper Yangtze River basin, accounting for $69 \%$ and $82 \%$ of the total station in the middle and lower Yangtze River basin respectively.

\subsection{Seasonal Extreme Precipitation Changes}

Summer (June to September) is the main flooding season of the Yangtze River basin. In this paper, percentile daily precipitation maxima (prec95p for $95^{\text {th }}$ percentile and prec 99 p for $99^{\text {th }}$ percentile) for summer season were accepted for detection of summer precipitation extreme in the Yangtze River basin.

Figure 5 indicates that the upper and lower Yangtze River basin are dominated by and total precipitation of prec95p in significant upward trend. The regions dominated by significant upward trend of total precipitation and frequency of prec95p are mainly the Yangtze Delta region and south-western part of the Yangtze River basin. The middle Yangtze River basin is dominated by significant downward trend of frequency of prec95p (the stations with precipitation in significant downward trend of frequency of prec95p account for about $52 \%$ of the total stations with frequency of prec95p in significant trend) (Figure 6). The spatial distribution of frequency and total precipitation of prec99p in the Yangtze River basin is similar to that of prec95p (Figure 7). South part of the Yangtze River basin is dominated by significant upward trend of total precipitation changes of prec99p; however the north part of the Yangtze River basin is dominated by downward trend of total precipitation changes of prec99p (Figure 7B, Figure 6). As for the 


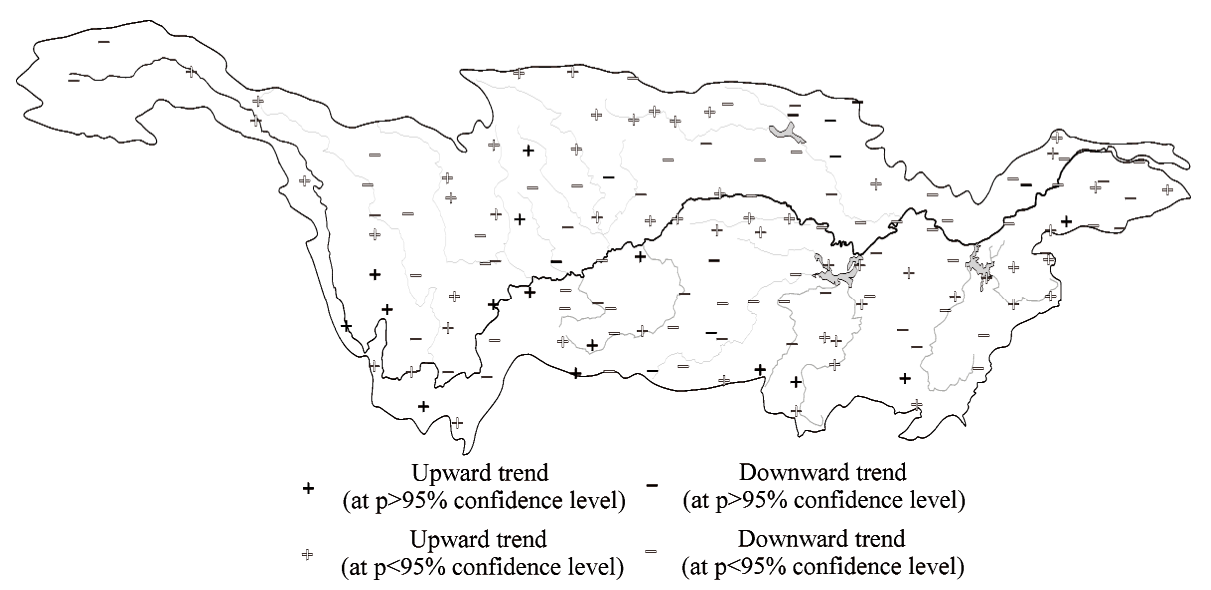

(A)

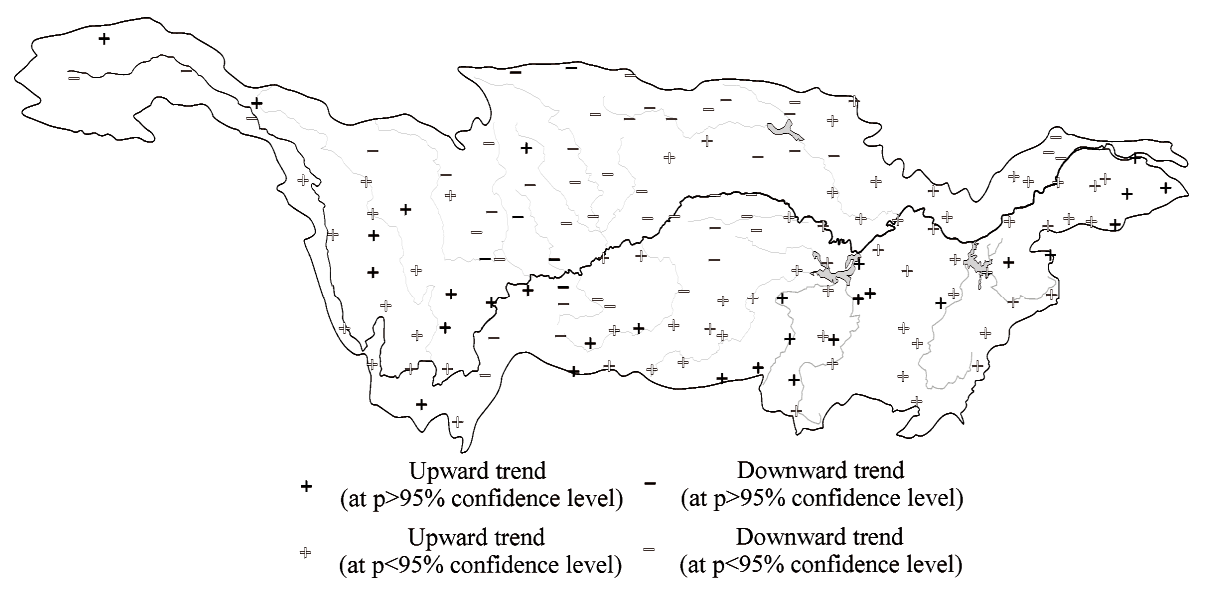

(B)

Figure 4. Spatial distribution of trends of highest 10-day precipitation amount. A: Frequency of highest 10-day precipitation amount; B: Total of highest 10-day precipitation amount.

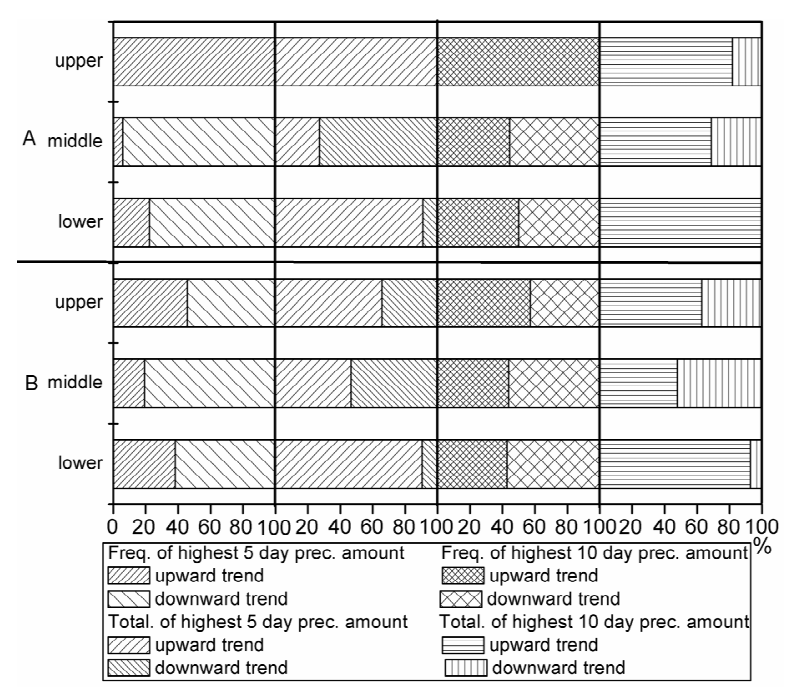

Figure 5. Ratio of stations with precipitation in upward/downward trend to the total stations (B) and ratio of stations with precipitation in significant upward/downward trend (>95\% confidence level) to the total stations with precipitations in significant upward/downward trend ( $>95 \%$ confidence level) in upper, middle and lower reaches of the Yangtze River basin respectively (A). 


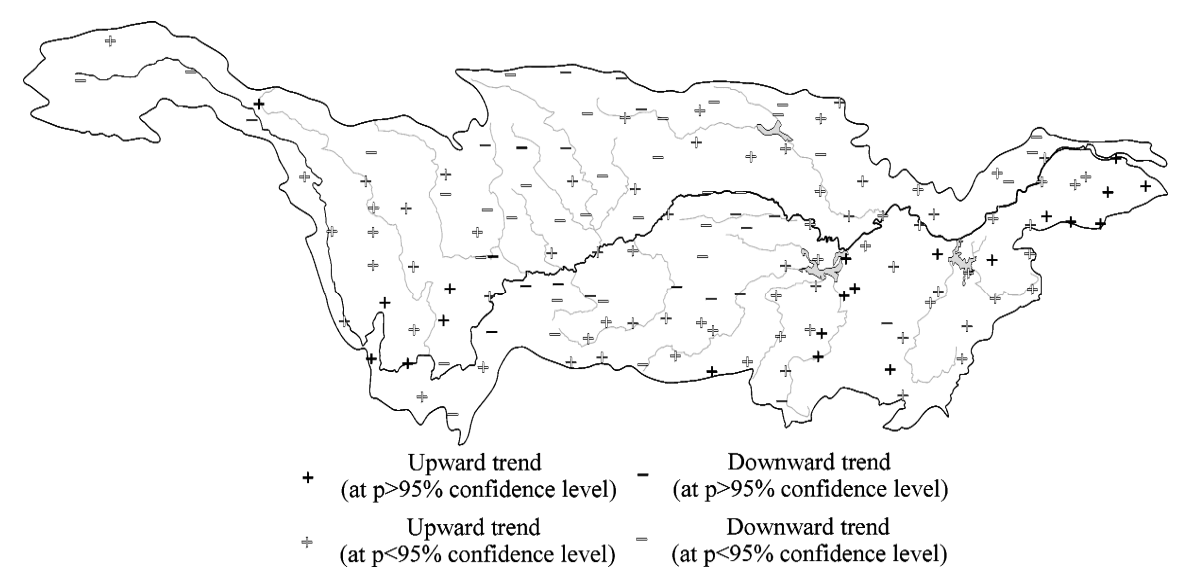

(A)

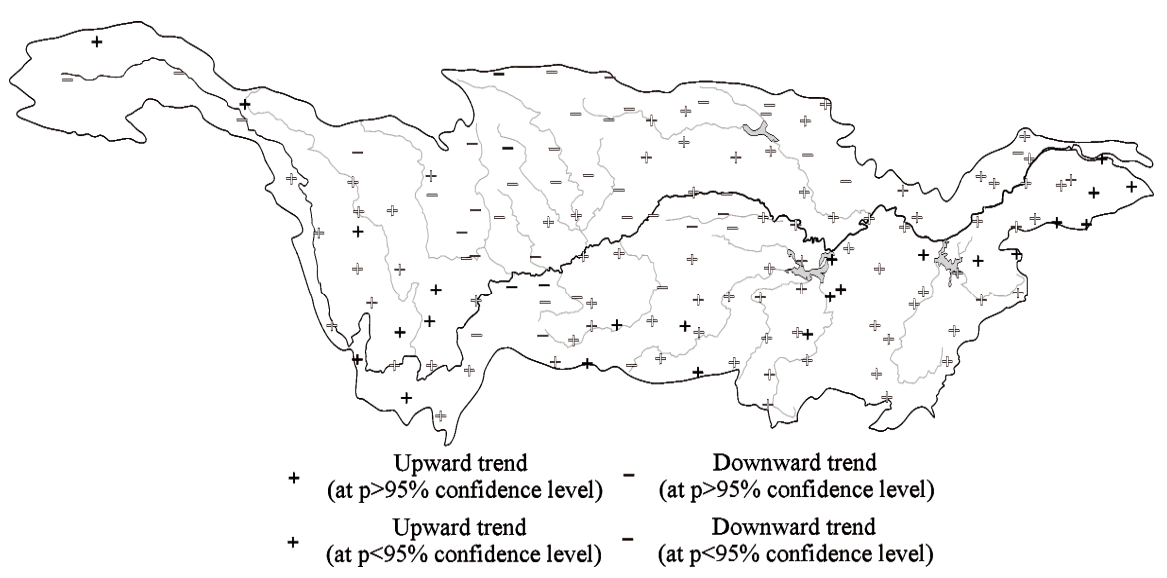

(B)

Figure 6. Spatial distribution of trends of $95^{\text {th }}$ percentile daily precipitation maxima. A: Frequency of $95^{\text {th }}$ percentile daily precipitation maxima; B: Total of $95^{\text {th }}$ percentile daily precipitation maxima.

changes of frequency of prec99p (Figure 7A), mostly stations with upward trends of precipitation of prec99p are concentrated in the lower Yangtze River basin and south-western part of the Yangtze River basin (Figure 6).

\section{Summary and Conclusions}

Extreme climatic events will exert tremendous influences on human society. Frequency and total precipitation of the highest 5 day and 10 day precipitation amount (R5D and R10D) and percentile daily precipitation maxima were analyzed with the help of linear trend analysis. Some interesting results were obtained: 1) the frequency of the highest 5-day and 10-day precipitation amount (R5D and R10D) was in downward trend, some stations are with frequency of R5D and R10D in significant downward trend, this phenomenon is more obvious in the middle Yangtze River basin; however the changes of the total precipitation of R5D and R10D are in upward trend. The stations with total precipitation of R5D and R10D are in significant upward trend ( $>95 \%$ confidence level) are mostly located in the lower Yangtze River basin and the south-western part of the Yangtze River basin; 2) the spatial distribution of the frequency of total precipitation of the percentile daily precipitation maxima is similar to that of R5D and R10D. What is different is that the frequency of prec95p and prec99p is in significant upward trend. However the upward trend of total precipitation changes of prec $95 p$ and prec99p is more obvious than that of frequency of prec95p and prec99p. The regions dominated by upward trend of frequency/total precipitation of prec95p and prec99p are also the lower Yangtze River basin and south-western part of the Yangtze River basin; 3 ) the global warming greatly influenced the spatial distribution pattern of the precipitation changes in the Yangtze River basin of China. More intensified precipitation will occur to the south-western part of the Yangtze River basin and lower Yangtze River basin. Therefore, the occurrence probability of the flash floods in the lower Yangtze River basin and south-western part of the Yangtze River basin will be greater. Furthermore, the Yangtze Delta region is geomorphologically low-lying, 


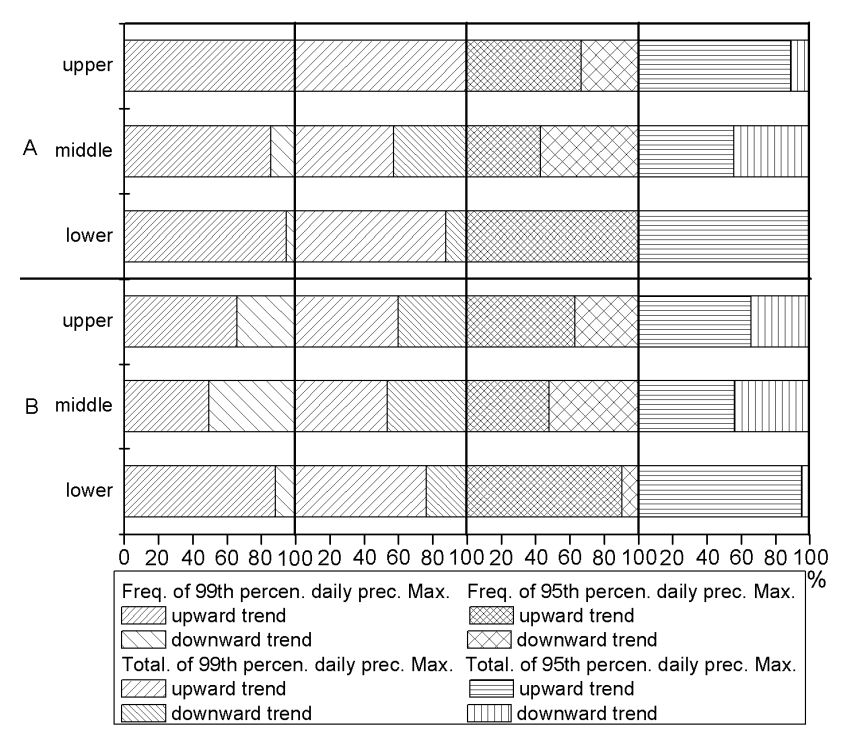

Figure 7. Ratio of stations with summer (June - September) precipitation in upward/downward trend to the total stations (B) and ratio of stations with summer (June - September) precipitation in significant upward/downward trend (>95\% confidence level) to the total stations with precipitations in significant upward/downward trend ( $>95 \%$ confidence level) in upper, middle and lower reaches of the Yangtze River basin respectively (A).

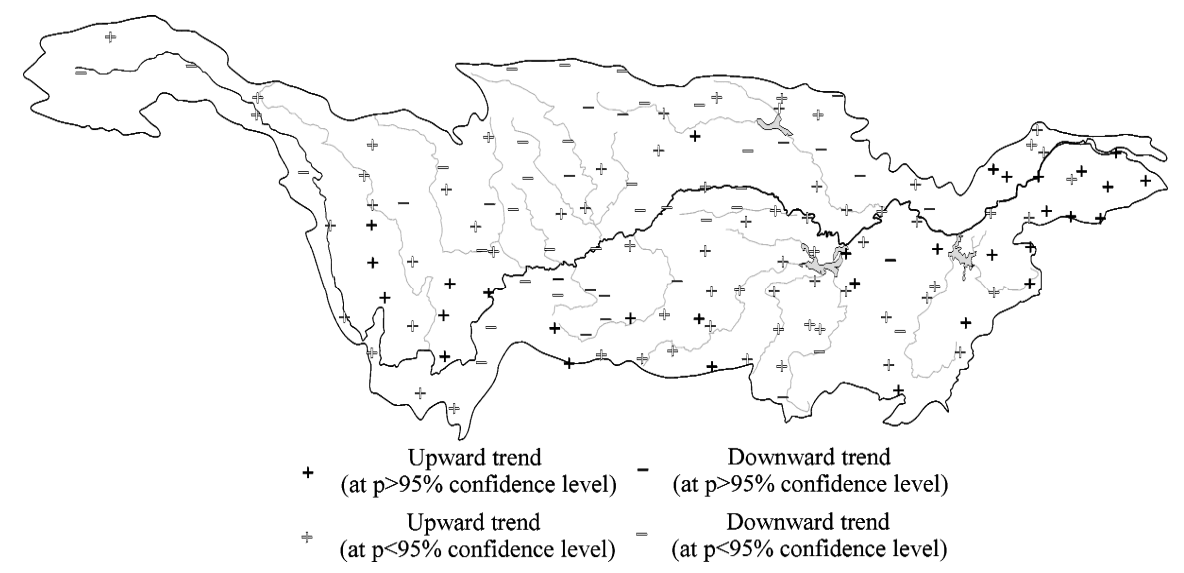

(A)

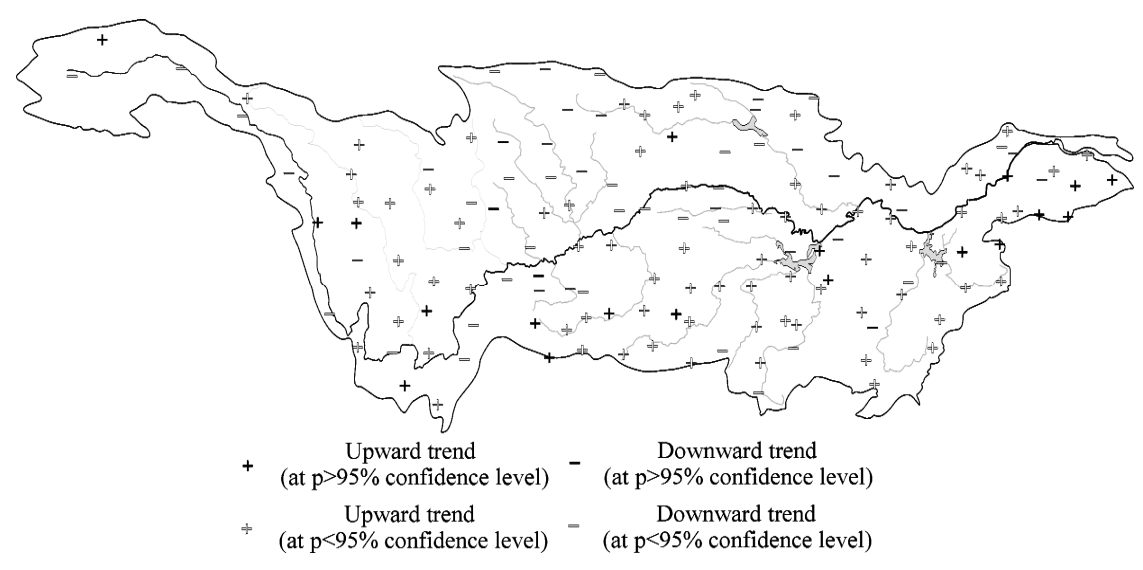

(B)

Figure 8. Spatial distribution of trends of $99^{\text {th }}$ percentile daily precipitation maxima. A: Frequency of $99^{\text {th }}$ percentile daily precipitation maxima; B: Total of $95^{\text {th }}$ percentile daily precipitation maxima. 
and prone to floods inundation and this region is one of the economically developed region in China. More good countermeasures will be necessary for future intensifying floods threats.

\section{Acknowledgements}

The work described in this paper was financially supported by the National Natural Science Foundation of China (Grant No.: 41071020), Project of the Guangdong Science and Technology Department (Grant No.: 2010B 050800001), the Program for Outstanding Young Teachers of the Sun Yat-sen University (Grant No.: 2009-370001132381), the Key National Natural Science Foundation of China (Grant No.: 50839005), a grant from the Research Grants Council of the Hong Kong Special Administrative Region, China (CUHK405308).

\section{References}

[1] B. C. Hewitson, “A Methodology for Developing Regional Climate Change Scenarios from General Circulation Models," WRC Report, Vol. 1, No. 594, 1997, pp. 35.

[2] D. Labat, Y. Goddéris, J. L. Probst, J. L. Guyot, "Evidence for Global Runoff Increase Related to Climate Warming," Advances in Water Resources, Vol. 27, 2004, pp. 631-642.

[3] A. M. Fowler, and K. J. Hennessy, "Potential Impacts of Global Warming on the Frequency and Magnitude of Heavy Precipitation," Natural Hazards, Vol. 11, 1995, pp. 283-303.

[4] A. O. Lucero, D. Rozas, "Characteristics of Aggregation of Daily Rainfall in a Middle-Latitudes Region during a Climate Variability in Annual Rainfall Amount," Atmospheric Research, Vol. 61, 2002, pp. 35-48.

[5] E. B. Horton, C. K. Folland, and D. E. Parker, "The Changing Incidence of Extremes in Worldwide and Central England Temperatures to the End of the Twentieth Century," Climate change, Vol. 50, 2001, pp. 67-295.

[6] N. Plummer, M. James, S. Neville, N. Ramasamy, "Changes in Climate Extremes over the Australian Region and New Zealand during the Twentieth Century," Climate Change, Vol. 42, 1999, pp. 183-202.

[7] P. Y. Groisman, T. Karl, D. Easterling, R. W. Knight, "Changes in the Probability of the Heavy Precipitation:
Important Indicators of the Climate Change," Climate Change, Vol. 42, 1999, pp. 243-283.

[8] T. R. Karl, R. W. Knight, and N. Plummer, "Trends in High-Frequency Climate Variability in the Twentieth Century," Nature, Vol. 377, 1995, pp. 217-220.

[9] D. R. Easterling, G. A. Meehl, C. Parmesan, S. A. Changnon, T. R. Karl, and L. O. Mearns, "Climate Extremes Observations, Modelling, and Impacts," Science, Vol. 289, 2000, pp. 2068-2074.

[10] Changjiang Water Resources Commission, Ministry of Water Resources(CWRC), "Waterlogging and Aridity Disasters in the Yangtze River Basins," Chinese Hydraulic Power and Electric Force Press, Beijing, 2002.

[11] Q. Zhang, T. Jiang, M. Germmer, S. Becker, "Precipitation, Temperature and Discharge Analysis from 1951 to 2002 in the Yangtze River Basin, China," Hydrological Sciences Journal, Vol. 50, No. 1, 2005, pp. 65-80.

[12] C. Jones, E. D. Waliser, M. K. Lau, W. Stern, "Global Occurrence of Extreme Precipitation and the Madden-Julian Oscillation: Observations and Predictability," American Meteorological Society, Vol. 17, 2004, pp. 4575-4589.

[13] R. W. Katz, and B. G. Brown, "Extreme Events in a Changing Climate: Variability is More Important than Average," Climatic Change, 21, 1992, pp. 289-302.

[14] R. Suppiah, and K. Hennessy, "Trends in the Intensity and Frequency of Heavy Rain in Tropical Australia and Links with the Southern Oscillation," Australian Meteorological Magazine, Vol. 45, 1996, pp. 1-17.

[15] R. D. Mora, C. Bouvier, L. Neppel, H. Niel, "Regional Approach for the Estimation of Low-Frequency of Low-Frequency Distribution of Daily Rainfall in the Languedoc-Roussillon Region, France," Hydrol. Sci. J., Vol. 50, No. 1, 2005, pp. 17-29.

[16] P. M. Zhai, A. J. Sun, F. M. Ren, "Changes of Climate Extremes in China," Climatic Change, Vol. 42, No. 1, 1999, pp. 203-218.

[17] T. A. Buishand, "Some Methods for Testing the Homogeneity of Rainfall Records," J. Hydrol., Vol. 58, 1982, pp. 11-27.

[18] J. L. Bell, L. C. Sloan, and M. A. Snyder, "Regional Changes in Extreme Climatic Events," Journal of Climate, Vol. 17, No. 1, 2004, pp. 81-87.

[19] S. N. Diffenbaugh, S. J. Pal, J. R. Trapp, F. Giorgi, "Fine-Scale Processes Regulate the Response of Extreme Events to Global Climate Change," Geophysics, Vol. 102, No. 44, 2005, pp. 15774-15778. 